Acta Universitatis Wratislaviensis No 3998

Anglica Wratislaviensia LVIII, Wrocław 2020

https://doi.org/10.19195/0301-7966.58.11

\author{
Michał Szawerna \\ ORCID: 0000-0002-1196-6834 \\ University of Wrocław \\ michal.szawerna@uwr.edu.pl
}

\title{
Modality, Medium, and More: A Toolkit for the Multimodal Cognitive Linguist. Sidenotes on Understanding Abstract Concepts across Modes in Multimodal Discourse: A Cognitive-Linguistic Approach (2020) by Elżbieta Górska
}

\begin{abstract}
The focus of this review article is on Understanding Abstract Concepts across Modes in Multimodal Discourse: A Cognitive-Linguistic Approach (2020), the latest monograph by professor Elżbieta Górska of Warsaw University, a leading Polish researcher in the area of multimodality studies informed by cognitive linguistics. The goal of this article is twofold. On the one hand, the article aims at evaluating Górska's monograph on its own merits, as a self-contained study of the cognitive processes involved in the interpretation of multimodal works of art by Janusz Kapusta, with an emphasis on conceptual metaphor, conceptual metonymy, and their interplay. On the other hand, the article aims at considering a number of thorny concepts underlying much of the current linguistically informed research into multimodal communication (notably, modality/mode, medium, and genre) by using Górska's monograph as a springboard for their discussion.
\end{abstract}

Keywords: multimodality, cartoons, metaphor, metonymy, modality, mode, medium, genre

In this review article, I look at Understanding Abstract Concepts across Modes in Multimodal Discourse: A Cognitive-Linguistic Approach (2020), the latest monograph by professor Elżbieta Górska of Warsaw University. The goal of this article is twofold. On the one hand, the article aims at evaluating Górska's monograph on its own merits, as a self-contained study of the processes involved in the interpretation of multimodal artwork created by Janusz Kapusta, a noted Polish visual artist working in America. On the other hand, the article aims at considering a number of thorny concepts underlying much of the current linguistically informed research 
into multimodal communication by using Górska's monograph as a springboard for their discussion.

The topic of Górska's monograph is situated at the crossroads of multimodality studies and cognitive linguistics, in a research area referred to as "multimodal cognitive linguistics" (Langlotz 55; Moya Guijarro 117). According to Pinar Sanz ("Multimodality" 2), multimodal cognitive linguistics is a major linguistic approach to analyzing various "modal ensembles" (Bezemer and Kress 6), that is, sign complexes which may take the form of long-lasting "semiotic artefacts" (Bateman 38) (photographs, advertisements, cartoons, comics, films, etc.) or rapidly fading, transitory (Hockett 6) products of multimodal interaction (such as the "verbo-gestural utterances" in Müller and Cienki 300). ${ }^{1}$ It seems that researchers working in the area of multimodal cognitive linguistics tend to draw on the interrelated frameworks of conceptual metaphor theory, initiated by Lakoff and Johnson, image schema theory, originally formulated by Johnson, and conceptual integration theory, also known as blending theory, articulated most fully by Fauconnier and Turner, in numerous explorations of the way in which diverse modal ensembles, including musical pieces, paintings, sculptures, advertisements, cartoons, and films, acquire meaning. This tendency is observable across a range of publications, including the studies written by Zbikowski, Cienki and Müller, Coëgnarts and Kravanja ("Embodied"), Kwiatkowska (Interfaces), Górska ("Multimodal Metaphors," "Dynamiczne podejście," "Up/Down Orientation"), Abdel-Raheem, and Szawerna (Metaphoricity), but also multiple contributions to the volumes edited by Libura, Forceville and Urios-Aparisi, Pinar Sanz (Multimodality), and Coëgnarts and Kravanja (Embodied Cognition).

In modelling the interpretation of Kapusta's artwork in terms of the quintessential cognitive linguistic frameworks of the theory of image schemas and conceptual metaphor theory, Górska's monograph perfectly embodies the kind of theoretical fusion of cognitive linguistics and multimodality studies that was advocated a few years ago by Alina Kwiatkowska ("A Plea for a Unified Cognitive-Semiotic Approach"). Specifically, Kwiatkowska argued that the semiotic makeup of visual representations, such as the ones included in Górska's (Understanding) scope of analysis, ought to be explored from the cognitive linguistic perspective for the reason that cognitive linguistics, understood as a paradigm subsuming multiple distinct, albeit overlapping, theories and research programs (van Hoek 134; Evans and Green 3), views the principles of linguistic organization as motivated by the principles of general cognition. In line with Kwiatkowska, I myself argued ("Cognitive Account" 139-40) that many theoretical concepts and descriptive instruments developed by cognitive linguists may be productively applied to the characterization of non-linguistically encoded meanings, with the broad applicability of these constructs and instruments following from a central tenet of cognitive linguistics

1 According to Pinar Sanz ("Multimodality" 2), other major linguistic approaches to analyzing multimodal ensembles include social semiotic multimodality, multimodal discourse analysis, and multimodal interactional analysis. 
whereby the meanings symbolized by linguistic expressions are shaped by the same mechanisms that guide non-linguistic cognition: notably, metaphor, metonymy, and conceptual integration. As demonstrated by a growing list of contributions to multimodal cognitive linguistics (Coëgnarts and Kravanja, "Visual Meaning"; Kwiatkowska, Interfaces; Górska, "Multimodal Metaphors," "Dynamiczne podejście," "Up/Down Orientation"; Szawerna, Metaphoricity; etc.), which not only shed light on the workings of multifarious modal ensembles, but also provide additional evidence for the psychological reality of various cognitive-linguistic concepts and instruments, Kwiatkowska's ("A Plea") idea of a fusion of cognitive linguistics and multimodality studies in the area of visual signification has proven descriptively fruitful as well as theoretically beneficial. Górska's monograph may not be unique in embodying Kwiatkowska's idea, but it is certainly no less descriptively fruitful or theoretically beneficial than the above-listed contributions to multimodal cognitive linguistics.

On the whole, then, Górska's latest monograph belongs to a well-established strand of linguistically informed research into multimodality that, on the one hand, has contributed to the understanding of how various modal ensembles are interpreted and, on the other hand, has provided additional evidence for the psychological reality of many concepts and instruments that were originally postulated by cognitive linguists on the basis of predominantly linguistic evidence. Structurally, the main body of Górska's monograph resolves into three chapters: an expository chapter titled "Introduction" and two analytical chapters, respectively titled "A Multimodal Case Study of EMOTION Concepts" and "A Multimodal Case Study of LifE." The monograph's main body is followed by a list of references and an index.

A major topic addressed in the expository chapter is the theory of image schemas. In this section, Górska (Understanding 1-7) refers to a number of seminal sources to highlight the key characteristics of image schemas: (1) their preconceptual as well as embodied nature, whereby image schemas emerge in early stages of infancy out of the infant's bodily interaction with the environment and then provide structure to experience and thought throughout ontogeny, and (2) their socio-cultural situatedness, whereby, on the one hand, image schemas shape meaning in multiple domains across societies and cultures and, on the other hand, are themselves shaped by various social and cultural influences. This is important because the following chapters are in large part devoted to a discussion of the ways in which various image schemas function as source domains of conceptual metaphors guiding the interpretation of Kapusta's artwork included in Górska's (Understanding) analytical scope. For this reason, however, it may seem a little surprising that there is no separate section on the theory of conceptual metaphor in the expository chapter of Górska's monograph; instead, the concepts and instruments of conceptual metaphor theory are largely taken for granted in this chapter, and their discussion is subordinated to the discussion of image schemas and their properties. But come to think of it, this choice on the part of Górska is in fact justified since the 
two theories overlap to such a degree that their overview in two consecutive sections would have likely resulted in a lot of unwelcome repetition.

In addition to the overview of the theory of image schemas, the expository chapter of Górska's monograph includes two consecutive sections discussing the data included in the scope of the analysis, the goals of the analysis, and the methodology adopted for the analysis. In a nutshell, Górska's main goal is twofold: (1) to describe the role of image-schematic metaphors and metonymies in the process whereby the overall understanding of Kapusta's visual works of art, dubbed "verbopictorial aphorisms" (Understanding 9), emerges in the mind of the recipient and (2) to specify the contribution of the image-schematic metaphors and metonymies to the interpretation of meaning communicated by means of "the verbal modality" (Understanding 12) and "the pictorial modality" (Understanding 12). This brings me to my first criticism of the monograph: the problematic notion of aphorism aside, ${ }^{2}$ it seems that the labelling of Kapusta's artwork as "verbo-pictorial" (Górska, Understanding 9), however convenient it may be as an analytical shorthand, oversimplifies the workings of these semiotically quite complex ensembles of visual signs.

The characterization of the written component of Kapusta's artwork as formulated in a single - verbal - modality is problematic for the commonly recognized reason that language may materialize in several non-identical ways, as speech, writing, tactile signs (as in Braille), and gestural signs (as in various signed languages), so that there is in fact no single verbal modality, but instead a few related modalities that share a number of verbal (or perhaps linguistic) characteristics: lexical content, morphological structure, syntactic structure, etc. One could of course argue that modalities are hierarchical (as in Bateman, Wildfeuer, and Hiippala 121-23; and Burn 8, see below) and that for this reason written language may be regarded as a single variety of the verbal modality - a verbal submodality if you like-were it not for the fact that writing is regularly used to create orthographic forms of non-linguistic signs in at least one narrative medium: comics. In comics exemplifying diverse publication formats, generic conventions, and cultural traditions, one-off written forms like skroww, baroom, kerashh, choom, and tschrak, ${ }^{3}$ which are not conventionalized enough to enjoy the status of written words (see Kowalewski 31), are deployed as representations of "sound effects" (Duncan and Smith 145). Given that language is regularly represented by means other than writing (speech, Braille, and signed languages) and, at the same time, written forms

2 It would have been interesting to learn from the monograph what motivated Górska (Understanding) to refer to Kapusta's multimodal artwork as aphorisms other than the fact that they constitute conceptual riddles solved for "the intellectual reward" of a new understanding of the aphorism's theme (Górska 74). Also, are multimodal aphorisms the sole province of Kapusta, or do they make up a more or less established genre of the medium of cartoons, practised by other artists as well? And if the latter is the case, what other genres should be distinguished within this medium?

3 These one-off written forms have been reproduced from a single comic-book anthology, titled X-Men: Supernovas (Carey et al.). 
need not represent linguistic expressions (as is the case with written sound effects in comics), so that language and writing may be completely divorced from each other, there are grounds for considering the verbal and the orthographic component of written language as separate modalities and, consequently, for considering written linguistic forms such as the ones found in Kapusta's visual artwork as being multimodal (or at least bimodal).

The characterization of the non-verbal component of Kapusta's works of art as formulated in a single - pictorial - modality is no less problematic in view of the fact that they feature semiotically diverse non-verbal signs. On the one hand, they contain signs which are uncontroversially pictorial (that is, visually mimetic) insofar as they exhibit imaginal iconicity in the sense of Charles Sanders Peirce (CP $\S 2.277),{ }^{4}$ whereby they "look like the thing they represent" (Miodrag 9). These uncontroversially pictorial signs include Kapusta's drawings of his pawn-like protagonist (Example 1.1, Górska, Understanding 13; Example 1.2, Górska, Understanding 14; etc.), blazing flames (e.g. Example 2.6, Górska, Understanding 35), a signpost (e.g. Example 3.1, Górska, Understanding 49), a stretcher bar (e.g. Example 3.12, Górska, Understanding 65), a tolling bell (e.g. Example 3.13, Górska, Understanding 66), and perhaps a few others. On the other hand, however, Kapusta's artwork contains a variety of arrows and lines (short as well as long, straight as well as bent, squiggly, etc.) which are not meant to be interpreted as Peircean imaginal hypoicons, but are instead intended to function as Peircean diagrammatic hypoicons, metaphorical hypoicons, indices of one kind or another, symbols, or combinations thereof (in short, visually non-mimetic signs). For instance, Kapusta's cartoon reproduced as Example 3.2 (Górska, Understanding 51) features his pawnlike protagonist situated on a line from which a number of other lines fan out. If this visual representation were interpreted in its entirety as an imaginal hypoicon, the cartoon would likely be taken to show the protagonist flying on a broom, Harry Potter-style (That's what it looks like!), but the verbal component "Chociaż mamy nieskończoną ilość dróg do wyboru i tak pójdziemy tylko jedną" (translated into English as "Even though we have an infinite number of paths to choose from, we will follow only one," Górska, Understanding 51) effectively blocks this interpretation by suggesting that the lines be understood as components of a diagrammatic as well as symbolic representation of a metaphorical path that forks into numerous other metaphorical paths. In other words, due to their semiotics, the arrows and lines featured in Kapusta's cartoons that are included in the scope of Górska's (Understanding) analysis are no more pictorial than the written messages included in these cartoons for the reason that both the former and the latter exhibit no imaginal iconicity in the sense of Peirce (CP § 2.277) despite their shared static visual form. For this reason, they should not be bundled up with the actual imaginal

4 The references to Peirce's Collected Papers indicate volumes and paragraphs. For example, “CP § 2.277” refers to volume 2, paragraph 277. 
hypoicons found in Kapusta's cartoons (i.e. the drawings of the pawn-like protagonist, blazing flames, the signpost, etc.) in a single category of pictorial signs.

On the whole, then, it seems that the term verbo-pictorial, which I believe originates from Forceville's (Pictorial Metaphor) seminal exploration of visual metaphoricity of advertisements, but has since been used by multiple researchers in the area of multimodality studies (e.g. Müller; Popa; Bakhtiar), cannot be treated as anything other than a convenient analytical shorthand when used with reference to hand-drawn works of art, such as the ones included in the scope of Górska's (Understanding) analysis. Its analytical usefulness notwithstanding, the term verbo-pictorial does obscure, as I hopefully demonstrated above, the rather more complex semiotic reality of the representations making up the artwork discussed by Górska (Understanding), which cannot be compartmentalized into two discrete categories, but are instead more realistically characterizable as making up a continuum of static visual signs that vary in terms of their semiotic makeup.

The preceding comments on the aptness of the term verbo-pictorial as a label describing Kapusta's artwork analyzed by Górska (Understanding) are of course an echo of the ongoing debate on what modalities (a.k.a. modes) $)^{5}$ are (and are not) in the context of multimodality studies. There are many definitions of modality available in published research on multimodality. Some of them have been instructively compiled by Bateman, Wildfeuer, and Hiippala (18). Taken at face value, these definitions seem to be less than fully satisfactory, but it is best remembered that Bateman, Wildfeuer, and Hiippala (18) extracted them out of their original contexts, which makes these definitions seem a little more problematic than they may have been originally. Be that as it may, there are a few reasons why they appear less than fully satisfactory. At least one of these definitions of modality seems factually incorrect ("the use of two or more of the five senses for the exchange of information" Granström, House, and Karlsson 1, ${ }^{6}$ qtd. in Bateman, Wildfeuer, and Hiippala 18). Another lists more or less randomly selected examples of modality in lieu of circumscribing the concept's definitional boundaries ("image, writing, gesture, gaze, speech, posture" Jewitt $1,{ }^{7}$ qtd. in Bateman, Wildfeuer, and Hiippala 18). A couple of other definitions are general to the point where they cannot be used to distinguish between the concept of modality and the related notion of medium ("a regularised organised set of resources for meaning-making" Jewitt and Kress $1,{ }^{8}$ qtd. in Bateman, Wildfeuer, and Hiippala 18; "a socially shaped and culturally given resource

5 The terms modality and mode are often used interchangeably in multimodality studies (see, for example, Bateman, Wildfeuer, and Hiippala 18). For reasons of simplicity, I will henceforth use the term modality.

${ }^{6}$ B. Granström, D. House and I. Karlsson (eds.). 2002. Multimodality in Language and Speech Systems. Dordrecht-Boston, MA-London: Kluwer Academic Publishers.

7 C. Jewitt (ed.). 2014. The Routledge Handbook of Multimodal Analysis. 2nd ed. London-New York, NY: Routledge.

8 C. Jewitt and G. Kress. 2003. Multimodal Literacy [New literacies and digital epistemologies, vol. 4]. Frankfurt am Main et al.: Peter Lang. 
for making meaning" Kress 79, ${ }^{9}$ qtd. in Bateman, Wildfeuer, and Hiippala 18). Last but not least, Forceville ("Non-verbal" $382,{ }^{10}$ qtd. in Bateman, Wildfeuer, and Hiippala 18) strikes a decidedly capitulatory note when he declares modality to be a definitional impossibility ("it is at this stage impossible to give either a satisfactory definition of 'mode', or compile an exhaustive list of modes").

Defining modality may well be a daunting task, not least because what seems to qualify as one modality may function quite differently across media, ${ }^{11}$ but, pace Forceville ("Non-verbal" 382), it is perhaps not entirely an impossible one if modality is conceived of as being characterizable as a combination of values along several parameters.

One such proposal was put forward by Bateman, Wildfeuer, and Hiippala (113-17), who managed to overcome the definitional problems discussed above by proposing that modalities be characterized as a combination of values along the parameters of materiality, semiotics, and discoursivity. Materiality refers to the fact that modalities are manifested as signs, which need to have a material form if they are to be perceived and interpreted by their users, so that knowing a modality presupposes the knowledge of its material manifestations as signs. Examples include celluloid for film, paper for photographs, stone for sculptures, etc. In turn, semiotics specifies how signs in any modality relate their form to their meaning. For instance, a photograph looks like what it represents and therefore qualifies as a Peircean imaginal hypoicon (CP $\$ 2.277)$, an arrow sign points to its referent and therefore qualifies as a Peircean index (CP § 3.361; Nöth 114), and a piece of alphabetic writing signifies by convention and therefore qualifies as a Peircean symbol (see Peirce, unpublished manuscript no. L 75; also see CP § 2.249). Lastly, discoursivity covers such contextual factors as the knowledge and resources that are necessary to produce signs in various modalities, the socially and culturally recognized uses of signs produced in various modalities, and the socially and culturally accepted ways of receiving signs produced in various modalities.

A moment's reflection shows that Bateman, Wildfeuer, and Hiippala's (113-17) multidimensional conception of modality is flexible enough to allow a distinction between signs in any two modalities, no matter how closely related. For instance, the pawn-like protagonist and the arrows found in Kapusta's artwork reproduced by Górska (Understanding 13) in Example 1.1 may be alike in terms of their mater-

${ }^{9}$ G. Kress 2010. Multimodality: A Social Semiotic Approach to Contemporary Communication. London-New York, NY: Routledge.

10 C. Forceville 2006. "Non-verbal and Multimodal Metaphor as a Cognitivist Framework: Agendas for Research.” In: Kristiansen, G., M. Achard, R. Dirven and F. J. Ruiz de Mendoza Ibáñez (eds.). 2006. Cognitive Linguistics: Current Applications and Future Perspectives. Berlin: Mouton de Gruyter, 379-402.

11 As I pointed out above, in comics writing is used in a unique fashion. In this narrative medium, writing is regularly used to create orthographic forms of nonlinguistic signs: one-off written representations of "sound effects" (Duncan and Smith 145), such as skroww, baroom, kerashh, etc., which are rarely, if ever, found outside comics. 
iality (ink on paper) and discoursivity (hand-drawn by the artist as components of a thought-provoking multimodal riddle), but they are very different in terms of their semiotic makeup. Characterized in terms of Peirce's theory of signs, the pawn-like protagonist functions as a visually mimetic sign due to its imaginal hypoiconicity, whereas the arrows are visually non-mimetic signs which simultaneously exhibit indexicality, symbolicity, and metaphorical hypoiconicity.

A realistic characterization of modality would not be complete if it failed to recognize the hierarchical nature of modalities, whereby they vary along the parameter of generality/specificity, which in turn leads to the emergence of entire taxonomies of modalities. While the hierarchicality of modalities was not recognized in any of the available definitions referred to above, it is addressed by Bateman, Wildfeuer, and Hiippala (121-23) as well as other researchers into multimodality. For instance, for the narrative medium of film Burn (8) proposes a four-tiered taxonomy of modalities. At the highest, most general level, the taxonomy features the so-called orchestrating and contributory modalities. The former are then divided into filming and editing, and the latter into embodied, auditory, and visual modalities. At the next level, these more specific modalities are further resolved into even more specific categories. For filming, Burn (8) proposes frame, angle, and proximity; for editing - segment, transition, and counterpoint; for the embodied modality — dramatic action and speech; for the visual modality — lighting and set design; etc. Finally, at its lowest level Burn's (8) taxonomy subdivides dramatic action into gesture, facial expression, movement, etc.; speech into lexis, grammar, tone-tonicity, etc.; lighting into direction, intensity, focus, etc.; and so on.

But modality is not the only basic concept of multimodality studies that has received a somewhat superficial treatment in Górska's monograph, where not only modality (a.k.a. mode), but also medium and genre are neither defined nor situated with relation to one another. Instead, the terms modality/mode, medium, and genre seem to be used largely intuitively and more or less interchangeably throughout the monograph, with the result that the reader feels at a loss as to how these terms are to be understood. Górska (Understanding 1, 12, 15, 22, 29, 31, etc.) repeatedly speaks of the verbal and the pictorial modality (a.k.a. mode) as two distinct modalities (a.k.a. modes) characterizing Kapusta's artwork included in the book's analytical scope. This is in itself somewhat problematic because, as shown above, there are grounds for considering writing to be multimodal (or at least bimodal) rather than monomodal, and the non-verbal signs found in the artwork analyzed by Górska are semiotically too diverse (decidedly mimetic vs. decidedly non-mimetic) to be bundled up in a single category of pictorial signs. More importantly, however, Górska also speaks of "the verbal medium" (2020: Understanding 9, emphasis mine), "the pictorial medium" (Understanding 22, emphasis mine), "the static visuo-spatial modality of cartoons" (Understanding 29, emphasis mine), "the visual mode" (Understanding 22, emphasis mine), "the visual medium" (Understanding 9, emphasis mine), "the gestural medium" (Understanding 1, emphasis mine), and "co- 
occurring semiotic modes, such as gestures or pictures" (Understanding 10, emphasis mine). This interchangeable use of the terms modality (a.k.a. mode) and medium leaves the reader confused, and the confusion is compounded by the fact that Gorska also speaks of "the medium of film" (Understanding 64, emphasis mine), "the genre of film" (Understanding 63, emphasis mine), "cartoons as a genre" (Understanding 8, 73, 74; emphasis mine), "a more specific cartoon-genre of verbo-pictorial aphorisms" (Understanding 9, emphasis mine), and "a more specific genre of verbo-pictorial aphorisms" (Understanding 1, 74; emphasis mine). The above quotations show that, on the one hand, the same concepts are referred to throughout Górska's monograph with different terms (the pictorial/verbal/visual/gestural modality/mode as well as medium, the medium as well as genre of film) and, on the other hand, different concepts are referred to throughout the monograph with the same terms (the medium of film/gestures/pictures/verbal expressions/vision, the genre of cartoons/verbo-pictorial aphorisms). This has unwelcome consequences. For example, whatever Górska (Understanding) considers film to be is referred to in the book both as a medium and a genre, and it is moreover considered, counter to intuition and experience, on par with gestures, pictures, and vision, which are also referred to as media in the monograph.

In view of the above, it becomes apparent that Górska's monograph would have benefited from a section circumscribing the intended definitional boundaries of modality (a.k.a. mode), medium, and genre (but also sign and text, see below) and relating these terms to one another as components of the author's terminological system. In combination with what was previously said on the topic of modality, the following three paragraphs sketch out this kind of system on the basis of widely available academic sources.

In opposition to modality, which, as shown above, characterizes a single means of expressing meaning, medium is often used with reference to a combination of modalities. This follows not only from the characterization of media in multimodality studies (Bateman, Wildfeuer, and Hiippala 123-28), but also from the way this term is used in transmedial narratology (e.g. Ryan), film studies (e.g. Burn), and comics scholarship (e.g. McCloud; Duncan and Smith). The number of modalities a medium has at its disposal may be difficult to specify with precision, mostly due to the multiplicity of available definitions of modality (see above), which in turn makes the existence of monomodal media a contentious topic, but media certainly vary in terms of how many modalities they employ (For instance, compare a novel and a film.). Also, typically one of the modalities dominates over others in a given medium, a characteristic referred to by Norris as modal density. For example, the medium of film is predominantly visual (In fact, films were silent for over two decades, in the period 1894-1929.), while the medium of opera is predominantly auditory (It is a standard practice to release audio-only recordings of operas on vinyl records and compact discs.). Irrespective of their internal variation, all media exhibit certain common features, emphasized by Ryan (15-20) and Bateman, Wildfeuer, 
and Hiippala (123-28): their form is to some extent constrained by technology, they are historically established, culturally accepted, passed on from generation to generation, etc.

There is, however, one respect in which media resemble modalities. Both terms describe potentialities that may be materialized. While modalities are materialized as signs, understood broadly (as in, for example, Peirce's theory of signs), media are materialized as texts (in the extended sense of text, encompassing not only spoken and manuscript/printed language, but also drawings, paintings, sculptures, photographs, films, comic books, operas, theatrical performances, etc., cf. Post 20). Importantly, a sign inherits its properties from the corresponding modality, so that signs may be visual, auditory, tactile, etc., and texts inherit their properties from media, so that a comic book qualifies as a material manifestation of the comics medium, a photograph qualifies as a material manifestation of the medium of photography, a movie qualifies as a material manifestation of the medium of film, etc.

As regards the concept of genre, it is usually distinguished from the concept of medium by being characterized as an inherently relational category. Specifically, a genre acts as an intermediate between a text and the corresponding medium (literature, film, comics, etc.). According to Ryan, "the difference between medium and genre resides in the nature and origin of the constraints that relate to each of them. Whereas genre is defined by more or less freely adopted conventions, chosen for both personal and cultural reasons, medium imposes its possibilities and limitations on the user" (19, original emphasis). The user's relative freedom of choice with regard to genre conventions confers the status of a stylistic category on genre. The "more or less freely adopted" genre conventions referred to by Ryan (19) may pertain to various levels of representation characterizing a text, broadly understood: the compositional level, the thematic level, the axiological level, etc. (cf. Post 22). This in turn accounts for the fact that genres are dependent on media to a greater or lesser extent. For example, the genres of western, horror, and science fiction are relatively autonomous and can be found in literature, film, comics, video games, radio drama, and even theater, while it is hard to imagine the more dependent genre of musical outside film or theater. This also accounts for the fact, emphasized by, for example, Costanzo in the context of film and Duncan and Smith (217-18) in the context of comics, that genres can be blended (in the sense of blending theory, see Fauconnier and Turner), which results in the emergence of generically hybrid films (Alien, Cowboys and Aliens, Overlord) and comics (Maus: A Survivor's Tale, From Hell, The League of Extraordinary Gentlemen), but also texts in other media (novels, video games, radio dramas, etc.).

While Górska's inclusion in her monograph of a section circumscribing the intended definitional boundaries of the basic terminology of multimodality studies would have prevented the confusion caused by the author's intuitive and more or less interchangeable use of the terms modality (a.k.a. mode), genre, and medium, it must be stressed that its absence takes relatively little away from Górska's overall 
accomplishment, evaluated with relation to the monograph's goal specified in the expository chapter. As I explained above, Górska's goal was twofold: (1) to describe the role of image-schematic metaphors and metonymies in the process whereby the interpretation of Kapusta's artwork emerges in the mind of the recipient and (2) to specify the contribution of the image-schematic metaphors and metonymies to the interpretation of meaning communicated through what Górska (Understanding 12) refers to as "the verbal modality" and "the pictorial modality." In the two analytical chapters, titled "A Multimodal Case Study of Emotion Concepts" and "A Multimodal Case Study of LIFE," Górska shows, with admirable attention to detail, how image schemas used as source domains of conventional as well as creative metaphors cue various elements of the abstract target domains (EMOTIONS and LIFE), in this way facilitating the recipient's understanding of Kapusta's visual artwork included in the scope of Górska's analysis. What I find particularly noteworthy about the analytical chapters is that Górska painstakingly anatomizes multiple works of art to show the variable contribution of their verbal and non-verbal components as the two, in some cases complementary and in others overlapping, channels used by Kapusta to cue the abstract target domains of EMOTIONS and LIFE by means of various image schemas. This in turn allows Górska to assess the level of activation of the particular image-schematic metaphors in the process whereby they facilitate the recipient's understanding of a given work of art and to label them as 'sleeping' or 'waking,' in accordance with Müller's dynamic approach to metaphor. The broad range of Kapusta's works of art subjected to analysis has allowed Górska to reveal cases where non-verbal metaphorization of the abstract target domains of EMOTIONS and LIFE is largely independent from their verbal metaphorization, which further substantiates the cognitive-linguistic view of metaphor as a modality-independent conceptual mechanism. Metaphors aside, the case studies in the analytical chapters of Górska's monograph contribute to our understanding of the key role played by conceptual metonymies in the interpretation of non-verbal representations. In particular, the case studies show time and time again how conceptual metonymies enable Kapusta to overcome the representational limitations of his static medium of choice by facilitating the understanding of static non-verbal signs as representations of dynamic events.

To conclude, despite the reservations and criticisms expressed in the preceding paragraphs, Górska's monograph deserves to be regarded as a descriptively fruitful and theoretically beneficial embodiment of Kwiatkowska's ("A Plea") idea of the cross-fertilization of cognitive linguistics and multimodality studies in the area of visual signification and multimodal communication. In particular, Górska has succeeded in demonstrating that for purposes of multimodal communication the artist Kapusta regularly draws on image-schematic metaphors and metonymies that have been conventionalized in language, but he also makes creative use of the unique affordances of his non-verbal resources by introducing image-schematic metaphors that have no established linguistic counterparts and would be difficult, 
if not downright impossible, to express in language. This is important for multimodality studies as well as cognitive linguistics because it shows, on the one hand, that research into non-verbal representations can greatly benefit from the accomplishments of cognitive linguists, and, on the other hand, that cognitive linguists cannot refrain from looking at non-verbal representations if they hope to arrive at a fully-fledged theory of conceptual metaphor.

\section{References}

Abdel-Raheem, A. 2019. Pictorial Framing in Moral Politics: A Corpus-Based Experimental Study [Routledge Studies in Multimodality]. London-New York, NY: Routledge.

Abrams, J. J. and L. Weber (Producers), and J. Avery (Director). 2018. Overlord [Motion picture]. USA: Bad Robot and Paramount Pictures.

Bakhtiar, M. 2017. "A Cognitive Linguistics Analysis of Baby-Boom Promoting Billboards in Iran." In: Grygiel, M. (ed.). Cognitive Approaches to Specialist Languages. Newcastle upon Tyne: Cambridge Scholars Publishing, 274-303.

Bateman, J. A. 2008. Multimodality and Genre: A Foundation for the Systematic Analysis of Multimodal Documents. Basingstoke-New York, NY: Pelgrave Macmillan.

Bateman, J., J. Wildfeuer and T. Hiippala. 2017. Multimodality: Foundations, Research and Analysis. A Problem-Oriented Introduction. Berlin-Boston, MA: Mouton de Gruyter.

Bezemer, J. and G. Kress. 2016. Multimodality, Learning and Communication: A Social Semiotic Frame. London-New York, NY: Routledge.

Burn, A. 2017 [2013]. "The Kineikonic Mode: Towards a Multimodal Approach to Moving Image Media.” In: Jewitt, C. (ed.). The Routledge Handbook of Multimodal Analysis. London-New York, NY: Routledge, 375-86.

Carey, M., C. Bachalo, H. Ramos and M. Brooks. 2007. X-Men: Supernovas. New York, NY: Marvel Publishing.

Carroll, G., D. Giler, W. Hill (Producers) and R. Scott (Director). 1979. Alien [Motion picture]. USA: Brandywine Productions and Twentieth Century-Fox Film Corporation.

Cienki, A. and C. Müller. 2008. “Metaphor, Gesture, and Thought.” In Gibbs, R. W., Jr. (ed.). 2008. The Cambridge Handbook of Metaphor and Thought. Cambridge et al.: Cambridge UP, 483-501.

Coëgnarts, M. and P. Kravanja. 2012. "Embodied Visual Meaning: Image Schemas in Film." Projections: The Journal of Movies and Mind 6.2. 84-101.

Coëgnarts, M. and P. Kravanja (eds.). 2015. Embodied Cognition and Cinema. Leuven: Leuven UP.

Cohen, B. and J. Favreau (Producers), and J. Favreau (Director). 2011. Cowboys and Aliens [Motion picture]. USA: Universal Pictures, DreamWorks, Reliance Entertainment, Relativity Media, Imagine Entertainment, K/O Paper Products, Fairview Entertainment, Platinum Studios, and K/O Camera Toys.

Costanzo, W. V. 2014. World Cinema through Global Genres. Oxford-Malden, MA: John Wiley and Sons.

Duncan, R. and M. J. Smith. 2009. The Power of Comics: History, Form and Culture. New York, NY-London: Continuum.

Evans, V. and M. Green. 2006. Cognitive Linguistics: An Introduction. Edinburgh: Edinburgh UP.

Fauconnier, G. and M. Turner. 2002. The Way We Think: Conceptual Blending and the Mind's Hidden Complexities. New York, NY: Basic Books.

Forceville, C. 1996. Pictorial Metaphor in Advertising. London-New York, NY: Routledge. 
—. 2006. "Non-verbal and Multimodal Metaphor as a Cognitivist Framework: Agendas for Research.” In: Kristiansen, G., M. Achard, R. Dirven, and F. J. Ruiz de Mendoza Ibáñez (eds.). 2006. Cognitive Linguistics: Current Applications and Future Perspectives. Berlin: Mouton de Gruyter, 379-402.

Forceville, C. and E. Urios-Aparisi (eds.). 2009. Multimodal Metaphor [Applications of Cognitive Linguistics, vol. 11]. Berlin-New York, NY: Mouton de Gruyter.

Górska, E. 2012. "Why are Multimodal Metaphors Interesting? The Perspective of Verbo-visual and Verbo-musical Modalities.” In: Kuźniak, M., A. Libura and M. Szawerna (eds.). 2012. From Conceptual Metaphor Theory to Cognitive Ethnolinguistics: Patterns of Imagery in Language [Studies in Language, Culture and Society, vol. 3]. Frankfurt am Main et al.: Peter Lang, 17-36.

—. 2014a. "Dynamiczne podejście do metafory" [A dynamic approach to metaphor]. Prace Filologiczne 64.2. 109-22.

—. 2014b. "The Up/Down Orientation in Language and Music.” In: Brenzinger, M. and I. KraskaSzlenk (eds.). 2014. The Body in Language: Comparative Studies of Linguistic Embodiment [Brill's Studies in Language, Cognition and Culture, vol. 8]. Leiden and Boston, MA: Brill, 177-95.

—.2020. Understanding Abstract Concepts across Modes in Multimodal Discourse: A CognitiveLinguistic Approach. New York, NY: Routledge.

Hockett, C. F. 1982 [1960]. “The Origin of Speech.” Reprint. In: Wang, W. S.-Y. (ed.). 1982. Human Communication: Language and its Psychobiological Bases. San Francisco, CA: W. H. Freeman, 4-12 / Scientific American 203. 88-111.

Johnson, M. 1987. The Body in the Mind: The Bodily Basis of Meaning, Imagination, and Reason. London-Chicago, IL: The U of Chicago P.

Kowalewski, H. 2015. "From Icono-Linguistic Unity to Semiotic Continuity: An Alternative Description of Semiotic Repertoire of Comics." International Journal of Comic Art 17.1. 24-44.

Kwiatkowska, A. 2011. "A Plea for a Unified Cognitive-Semiotic Approach to the Analysis of Verbal and Visual Representations." Kwartalnik Neofilologiczny 3. 313-24.

—. 2013. Interfaces, Interspaces: Image, Language, Cognition. Piotrków Trybunalski: Naukowe Wydawnictwo Piotrkowskie przy Filii Uniwersytetu Jana Kochanowskiego.

Lakoff, G. and M. Johnson. 1980. Metaphors We Live By. London-Chicago, IL: The U of Chicago P.

Langlotz, A. 2015. "Language, Creativity, and Cognition." In: Jones, R. H. (ed.). 2015. The Routledge Handbook of Language and Creativity. London-New York, NY: Routledge, 40-60.

Libura, A. (ed.). 2007. Amalgamaty kognitywne w sztuce [Cognitive blends in the arts]. Kraków: Universitas.

McCloud, S. 1994 [1993]. Understanding Comics: The Invisible Art. Reprint. New York, NY: HarperPerennial-Northampton, MA: Tundra Publishing.

Miodrag, H. 2013. Comics and Language: Reimagining Critical Discourse on the Form. Jackson, MS: UP of Mississippi.

Moore, A. and E. Campbell. 1999 [1991-1998]. From Hell. Marietta, GA: Top Shelf Productions / From Hell \#1-11. Princeton, WI; Northampton, WA: Kitchen Sink Press.

Moore, A., K. O'Neill, W. Oakley and B. Dimagmaliw. 2003 [2002-2003]. The League of Extraordinary Gentlemen. vol. 2. La Jolla, CA: America's Best Comics (DC Comics) / The League of Extraordinary Gentlemen. vol. 2. \#1-6.

Moya Guijarro, A. J. 2015 [2013]. "Visual Metonymy in Children's Picture Books.” In: Pinar Sanz, M. J. (ed.). 2015. Multimodality and Cognitive Linguistics [Benjamins Current Topics, vol. 78]. Amsterdam-Philadelphia, PA: John Benjamins, 115-130 / Review of Cognitive Linguistics 11.2. 336-52.

Müller, C. 2008. Metaphors Dead and Alive, Sleeping and Waking: A Dynamic View. Chicago, ILLondon: The U of Chicago P. 
Müller, C. and A. Cienki. 2009. "Words, Gestures, and Beyond: Forms of Multimodal Metaphor in the Use of Spoken Language.” In: Forceville, C. and E. Urios-Aparisi (eds.). 2009. Multimodal Metaphor [Applications of Cognitive Linguistics, vol. 11]. Berlin-New York, NY: Mouton de Gruyter, 297-328.

Norris, S. 2004. Analyzing Multimodal Interaction: A Methodological Framework. New York, NYLondon: Routledge.

Nöth, W. 1995 [1990]. Handbook of Semiotics. Bloomington, IN: Indiana UP.

Peirce, C. S. 1902. Unpublished manuscripts. Indiana University. (References to MS with number, year and pagination as in the files of the library.).

-. 1931-1958. Collected Papers of Charles Sanders Peirce. Vols. 1-6, ed. Hartshorne, C. and P. Weiss; vols. 7-8, ed. by Burks, A. W. Cambridge, MA: Harvard UP.

Pinar Sanz, M. J. (ed.). 2015. Multimodality and Cognitive Linguistics [Benjamins Current Topics, vol. 78]. Amsterdam-Philadelphia, PA: John Benjamins.

—. 2015 [2013]. "Multimodality and Cognitive Linguistics: Introduction.” In: Pinar Sanz, M. J. (ed.). 2015. Multimodality and Cognitive Linguistics [Benjamins Current Topics, vol. 78]. Amsterdam-Philadelphia, PA: John Benjamins, 1-9 / "Multimodality and Cognitive Linguistics: Introduction to the Special Volume." Review of Cognitive Linguistics 11.2. 227-35.

Popa, D. E. 2015 [2013]. "Multimodal Metaphors in Political Entertainment.” In: Pinar Sanz, M. J. (ed.). 2015. Multimodality and Cognitive Linguistics [Benjamins Current Topics, vol. 78]. Amsterdam-Philadelphia, PA: John Benjamins, 79-95 / "Multimodal Metaphors in Political Entertainment." Review of Cognitive Linguistics 11.2. 303-19.

Post, M. 2017. Film jako tekst multimodalny. Założenia i narzędzia jego analizy. Wrocław: Wydawnictwo Wyższej Szkoły Filologicznej we Wrocławiu.

Ryan, M.-L. 2004. “Introduction.” In: Ryan, M.-L. (ed.). 2004. Narrative across Media: The Languages of Storytelling [Frontiers of Narrative, vol. 3]. Lincoln, NE: U of Nebraska P, 1-40.

Spiegelman, A. 1986 [1980-1985]. Maus: A Survivor's Tale. Vol. 1. My Father Bleeds History. New York, NY: Pantheon Books / Maus \#1-6. New York, NY: Raw Books.

—. 1991 [1986-1991]. Maus: A Survivor's Tale. Vol. 2. And Here My Troubles Began. New York, NY: Pantheon Books / Maus \#7-11. New York, NY: Raw Books.

Szawerna, M. 2013. "On Developing a Cognitive Account of Comics.” In: Kuczyński, M. and L. Szymański (eds.). 2013. Language, Thought, and Education: Across Systems. Zielona Góra: Oficyna Wydawnicza Uniwersytetu Zielonogórskiego, 131-47.

- 2017. Metaphoricity of Conventionalized Diegetic Images in Comics: A Study in Multimodal Cognitive Linguistics [Łódź Studies in Language, vol. 54]. Frankfurt am Main et al.: Peter Lang.

van Hoek, K. 1999. "Cognitive Linguistics.” In: Wilson, R. A. and F. C. Keil (eds.). The MIT Encyclopedia of the Cognitive Sciences. Cambridge, MA-London: The MIT P, 134-35.

Zbikowski, L. 2002. Conceptualizing Music: Cognitive Structure, Theory, and Analysis [AMS Studies in Music, vol. 1]. Oxford et al.: Oxford UP. 